\title{
É possível falar de vocação quando se fala de ateísmo organizado? Reflexões sobre a iniciativa ateísta no Brasil
}

¿Es posible hablar de vocación cuando se habla de ateísmo organizado?

Reflexiones sobre la iniciativa atea en Brasil

Is it possible to speak about vocation when speaking of organized atheism?

Reflections on the atheist initiative in Brazil

Resumo

Diversos agrupamentos ateístas emergiram no Brasil nos últimos anos. Trata-se de pequenas associações que surgem a partir de e são mantidas graças à iniciativa de atores individuais que investem uma quantidade considerável de tempo, esforço e, inclusive, dinheiro para sustentar uma causa que, nem se define facilmente além da negação da ideia de deus, nem oferece recompensas materiais ou simbólicas aparentes. Este artigo procura explorar os sentidos que estes líderes ateístas atribuem à atividade militante, a partir de uma discussão sobre a categoria weberiana de vocação. Argumenta-se que a articulação de um movimento de descrentes, tal como se configura no Brasil, constitui uma empreitada intrinsecamente ambígua, na medida em que resiste toda formalização e definição para além do mínimo necessário para existir como tal. Sob o risco constante de devir "religião" o ateísmo não se organiza se não de forma embrionária, e dos seus articuladores exige um engajamento considerável
Sabrina F. Testa

Universidade Federal de Santa

Catarina, Florianópolis, Brasil.

$\square$ sabritesta@yahoo.com.ar

(1) ORCID: 0000-0003-3753-3946

An Google Scholar

Cómo citar este artículo:

Testa, S. F. (2021). É possível falar de vocação quando se fala de ateísmo organizado? Reflexões sobre a iniciativa ateísta no Brasil. Revista de Antropología y Sociología: Virajes, 23(2), 227-251.

https://doi.org/10.17151/rasv.2021.23.2.11 
que, no entanto, se evita definir em termos de liderança. A abordagem, de corte interpretativo, tem por base empírica um trabalho de campo etnográfico levado adiante entre setembro de 2016 e fevereiro de 2018 junto aos setores ateístas do Brasil.

Palavras chave: vocação, movimento ateísta, religião, iniciativa individual.

\section{RESUMEN}

Recientemente diversos agrupamientos ateístas emergieron en Brasil. Se trata de pequeñas asociaciones que surgen a partir de y son mantenidas gracias a la iniciativa de actores individuales, que invierten una cantidad considerable de tiempo, esfuerzo e, inclusive, dinero para sustentar una causa que, ni se define fácilmente más allá de la negación de la idea de Dios, ni ofrece recompensas materiales o simbólicas aparentes. Este trabajo busca explorar los sentidos que los líderes ateístas atribuyen a su actividad militante, a partir de una discusión sobre la categoría weberiana de vocación. Se argumenta que la articulación de un movimiento de increyentes, tal como se configura en Brasil, constituye un emprendimiento intrínsecamente ambiguo, en la medida en que resiste toda formalización y definición más allá de lo mínimo necesario para existir como tal. Bajo el riesgo constante de devenir "religión", el ateísmo no se organiza sino de forma embrionaria, y de sus articuladores exige un compromiso considerable que, no obstante, evita definirse en términos de liderazgo. El abordaje, de carácter interpretativo, tiene por base empírica un trabajo de campo etnográfico realizado entre septiembre de 2016 y febrero de 2018 en los sectores ateístas brasileños.

Palabras clave: vocación, movimiento ateísta, religión, iniciativa individual.

\section{ABstRact}

Recently, several atheistic groups have emerged in Brazil. These are small associations that arise and are sustained by the initiative of individual actors, who spend a considerable amount of time, effort and even money to the maintenance of a cause that is not easily defined beyond the negation of the idea of god, nor does it offer visible material or symbolic rewards. On the basis of a discussion on the Weberian category of vocation, this paper seeks to inquire about the meanings attributed to militant activity by the atheistic leaders of Brazil. This article argues that the articulation of a movement of unbelievers, as configured in Brazil, constitutes an intrinsically ambiguous undertaking, insofar as it resists all formalization and definition beyond the minimum necessary to exist as such. Under the constant risk of becoming "religion", atheism is only organized in an embryonic way, and from its articulators it demands a considerable commitment that, however, 
avoids defining itself in terms of leadership. The approach is interpretative and empirically based on ethnographic fieldwork carried out between September 2016 and February 2018 among Brazilian atheistic sectors.

Keywords: vocation, atheist movement, religion, individual initiative.

\section{Introdução}

- ste artigo apresenta algumas reflexões derivadas de minha tese de doutorado, defendida no Programa de Antropologia Social da Universidade Federal de Santa Catarina em março de 2020 (Testa, 2020). O trabalho esteve dedicado a explorar a articulação de um (autodenominado) movimento ateísta no Brasil, desenvolvimento aparentemente inédito surgido nos anos seguintes à virada do milênio. A pesquisa abordou não apenas a publicitação da descrença como posicionamento autoconsciente e explícito, mas também (e sobretudo) a sua instauração como motivo central de projetos coletivos no Brasil. O que interessava eram as tentativas observáveis de converter o ateísmo em algo mais do que uma convicção individual e privada ou um princípio puramente filosófico. O foco estava colocado no ateísmo organizado ou em vias de organização, nos ateus engajados e no misto de teoria e práxis que anima a ambos.

Mais especificamente, a pesquisa teve por objeto mapear a configuração de um campo ateísta no Brasil, atentando para suas variações e inter-relações internas e suas associações externas. O intuito era gerar uma descrição do ateísmo organizado em seu nível mais sobredeterminado: nas iniciativas, projetos e ações que o fazem existir como tal no cenário brasileiro. Por isso, se partiu da atividade concreta dos grupos, associações e iniciativas em geral que se formam e atuam em nome da descrença no Brasil. A base foi um trabalho de campo etnográfico multissituado, levado adiante entre setembro de 2016 e setembro de 2017. Este consistiu, basicamente, na observação participante de uma série de eventos explicitamente ateístas realizados em diversas cidades do país por diferentes grupos de ateus, formalizados ou não como associações. Incluiu também a observação de reuniões de comitês inter-religiosos de nível estadual e federal que contam com representação de ateus em sua composição'. 
Este artigo recolhe observações e reflexões derivadas deste processo. Em primeiro lugar, apresenta esclarecimentos relativos ao chamado movimento ateísta, relativamente desconhecido pelas ciências sociais latino-americanas. Em segundo lugar, explícita a abordagem teórico-metodológica, que foi desenhada em função das particularidades do objeto da pesquisa. O trabalho continua com uma síntese descritiva tanto do processo de pesquisa quanto das redes ateístas do Brasil, conforme foram se revelando ao longo do percurso. Aqui se procura colocar manifesto o caráter embrionário do movimento ateísta brasileiro em termos institucionais, a dificuldade que possui de constituir estruturas, mesmo grupos e, em contrapartida, a alta dependência de esforços essencialmente individuais. É digno de nota, com efeito, o investimento em termos de tempo, trabalho, e mesmo dinheiro realizado por aqueles que assumem para si a tarefa (quase uma missão) de criar e gerir projetos em nome do ateísmo.

O artigo finaliza com uma reflexão em torno deste engajamento, partindo do conceito weberiano de vocação (Weber, 1974; 2003). Com efeito, na sociologia clássica da religião, uma entrega semelhante é entendida em termos de vocação ou chamado divino, conceito que foi estendido a outras áreas, como a economia, a política ou a ciência (Weber, 1993). Em qualquer caso, se entende que os objetivos dessas empreitadas, ou então os benefícios derivados delas (terrenos ou ultraterrenos), justificam o tempo e os esforços investidos. Em termos weberianos, se entende que há valores ou fins mais ou menos claros que fazem compreensível o sentido da ação. No caso particular do ateísmo, não há, por definição, instância divina à qual apelar: não há paraíso, nem salvação possível nem necessária. Além disso, ao menos no contexto brasileiro, tampouco parece haver réditos materiais ou imateriais perceptíveis. É possível falar em vocação quando valores e fins não são evidentes e as definições desafiam as categorias conhecidas? Como entender o chamado que anima uma iniciativa definida a partir de uma negação? Como entender a vocação que anima os líderes ateístas num país que é claramente avesso à descrença²?

\footnotetext{
Com efeito, uma pesquisa da Fundação Perseu Abramo em parceria com o Instituto Rosa Luxemburgo realizada em 2008 , teve com resultado que $42 \%$ dos brasileiros sentem aversão aos ateus ( $17 \%$, ódio/ repulsa, e $25 \%$, antipatia), percentagem similar à dos usuários de drogas, com $41 \%$. Estes dois grupos lideram o ranking dos alvos de intolerância no Brasil. Fonte: Takata, R. (4 de agosto de 2010). Em nome da diversidade. Fundação Perseu Abramo. https://fpabramo.org.br/2010/08/04/em-nome-da-diversidade/
} 


\section{O movimento ateísta e sua abordagem teórico-metodológica}

Na prática, aquilo que -no Brasil- se convencionou em chamar de movimento ateísta se manifestou, em primeiro lugar, numa multiplicação das publicações sobre o assunto na mídia regular e, principalmente na Internet. No ciberespaço, no decorrer da primeira década do novo milênio, proliferaram rapidamente os sites, grupos, blogs, fóruns e discussão e similares dedicados ao ateísmo e seus afins. Em menor proporção, o movimento deu lugar à aparição de alguns eventos dedicados ao ateísmo e destinados a reunir descrentes e à constituição (ou tentativa de constituição) de algumas associações formais e outras iniciativas mais ou menos informais. Em todos os casos, o fim explícito é advogar pela aceitação pública do ateísmo como um posicionamento válido e digno de respeito, combater o preconceito contra os descrentes e, conjuntamente, agir em prol da laicidade do Estado. Este desenvolvimento se mostrava como uma novidade no Brasil, país conhecido pela sua vitalidade religiosa, e foi em função deste ineditismo que chamou a atenção de um punhado de pesquisadores locais. Estes não duvidaram em associar a recente movimentação descrente local ao que em arenas internacionais se conhece como "neo-ateísmo".

Com neo-ateísmo se faz referência a um movimento editorial, político e cultural surgido no Atlântico Norte após os atentados do 11 de setembro de 2001 (Gordon, 2011). Os inicios desta corrente são habitualmente ligados ao trabalho de um grupo de intelectuais conhecidos como os "quatro cavaleiros do ateísmo" em referência aos "quatro cavaleiros do Apocalipse" (Moreira, 2014, p. 11; Montero y Dullo, 2014). Os títulos de suas principais obras - "The God Delusion" (Dawkins, 2006, 2007), "The End of Faith: Religion, Terror and the future of Reason" (Harris, 2004), "Breaking the Spell: Religion as a Natural Phenomenon" (Dennet, 2006) y "God is not Great: How Religion Poisons Everything" (Hitchens, 2007, 2016)- oferecem uma aproximação ao tom das ideias que defendem. Em todos os casos, a característica central é uma crítica frontal e sem complexos da religião, baseada num discurso de confronto entre fé e razão e cunho claramente iluminista (Gordon, 2011).

Este boom editorial foi acompanhado pela popularização do tema na mídia regular e, notadamente, no ciberespaço, onde se multiplicaram os blogs, sites web, fóruns de discussão e similares dedicados ao proselitismo ateísta e à polêmica com setores religiosos. Ora, embora o ativismo cibernético seja a faceta mais estendida e também a mais visível do chamado neoateísmo, não o esgota. Este também compreende associações, ONGs, projetos e campanhas não limitadas ao mundo virtual. 
Especialmente nos países anglofalantes do hemisfério norte, o movimento se fez conhecido pela aparição pública de figuras como Dawkins e Harris, participantes frequentes de debates com representantes religiosos, pela realização de campanhas e eventos como a "Atheist Bus Campaign" lançada em Reino Unido e posteriormente replicada em vários países e pelo fortalecimento de entidades dedicadas ao humanismo secular, o ateísmo, o livre-pensamento, o secularismo e motivos similares, todas voltadas à legitimação da descrença, o combate ao preconceito e à separação entre igrejas e Estado.

Ora, há uma diferença a ser considerada entre o neo-ateísmo que se manifesta nos países anglofalantes do Atlântico Norte (que deram origem ao movimento e ao rótulo) e aquele que veio se desenvolver no Brasil mais ou menos contemporaneamente. Alhures o movimento assumiu feições e contornos bem definidos e, especialmente em seus desdobramentos extravirtuais, deu lugar a estruturas institucionais sólidas, capazes de lançar campanhas de larga escala e sustentar organizações perduráveis. No Brasil, pelo contrário, este não se organizou senão de forma embrionária, mesmo precária, sobretudo através de internet e com grandes dificuldades para desenvolver projetos além desta. Com efeito, uma das principais conclusões da tese foi que, no Brasil, o movimento ateísta caracteriza-se por uma sociogênese incompleta. Apesar das tentativas de constituir um movimento social, do projeto explícito de estruturar coletivos, constituir grupos e, no limite, formalizar associações, não consegue este resultado completamente.

É fato que no Brasil o movimento ateísta assume seus contornos mais definidos no ciberespaço. Em consequência, os poucos trabalhos que, no Brasil, abordaram o novo ateísmo desde uma perspectiva empírica tomaram como único campo de observação o ambiente virtual e estiveram interessados em equiparar o movimento ateísta local àquele que prospera no norte da Europa e da América, mais do que em compreender suas formas e sentidos locais (Fernandes, 2015; Franco, 2014). Foi esta lacuna que a tese elaborada procurou preencher ao propor uma pesquisa que abordasse o ateísmo brasileiro em seus próprios termos.

Perante um estado da questão e um referente empírico semelhantes, a proposta foi "seguir o curso da ação" levada adiante em nome da descrença partindo de alguns núcleos mais atuantes, para observar a constituição do ateísmo enquanto rede, isto é, enquanto trabalho sendo feito, fluxo, contingência, evento, associação (Latour, 2005). Neste sentido, o foco das observações foi colocado nas ideias e práticas dos ateus mobilizados em seu nível mais sobredeterminado. Não interessava qualquer 
dever ser ateísta particular, tampouco interessavam as visões autorizadas nem os ateus ilustres, mas observar aquilo que se faz e se diz em nome do ateísmo no dia a dia dos ativistas locais, mais ou menos anônimos, mais ou menos conhecidos. O intuito era captar as singularidades e heterogeneidades do ativismo ateísta do Brasil, sem pressupor definições nem modelos estabelecidos.

Esta estratégia esteve baseada a uma problemática inerente à questão do ateísmo: o problema de sua definição. Com efeito, como conceito estruturado a partir de uma negação o a-teísmo apresenta uma disjuntiva: tratar-se-ia, apenas de uma negação do teísmo, ou constituiria um posicionamento positivo e por direito próprio? A disjuntiva inscrita no termo se torna mais proeminente se considerarmos que a primeira leitura foi a preferida pelos diferentes cientistas sociais que se ocuparam do tema no Brasil, enquanto a segunda é defendida ativamente pelos próprios ativistas. Sem exceção, as pesquisas realizadas no Brasil sobre o ateísmo mobilizado contemporâneo coincidiram em englobar o fenômeno dentro da noção abrangente de religião, e isso em função, principalmente, das ideias da vanguarda neoateísta, que seriam qualitativamente análogas às crenças religiosas que tentam negar. Neste sentido, a Razão, a Ciência, o Homem ou mesmo a Natureza nada mais seriam -nas concepções de figuras como Dawkins e seus seguidores- do que emulações ou substitutos de um Deus transcendente que falham em eliminar.

Os próprios ativistas ateus, no Brasil e alhures, rejeitam ativamente esta dissolução conceitual do ateísmo na religião e o reivindicam como um posicionamento sui generis. Desde este ponto de vista, o ateísmo seria o denominador comum daquelas visões de mundo que prescindem de figuras divinas, fenómenos sobrenaturais e, em geral, de um plano entendido como transcendente, podendo em outros aspectos ter configurações diversas e origens filosóficas ao todo diferentes. Entende-se aqui que julgar, em termos teóricos, o sucesso ou fracasso efetivo de tais tentativas exigiria adentrar em discussões filosóficas e teológicas que excedem o recorte deste trabalho. Em todos os casos, em se tratando de um artigo inscrito nas ciências sociais e baseado numa pesquisa empírica em antropologia, o que interessa é tomar nota destas concepções e da maneira em que são mobilizadas cotidianamente, sem negar a priori a possibilidade de uma cosmologia sem deus, literal nem putativo.

Partindo disto, a pesquisa se propus explorar a disjuntiva sem resolvê-la. Para tanto, previu um movimento duplo: por um lado se deslocou o foco das observações das ideias ateístas -em particular as ideias dos intelectuais da vanguarda ateísta- para o que dizem e fazem 
em nome do ateísmo os ativistas vernáculos. Com isto se procurou não reduzir o ateísmo a uma filosofia (de certa forma, uma "a-teologia") e, ao mesmo tempo, não limitar os ateísmos existentes às formas consagradas do que internacionalmente se conhece como neo-ateísmo. Sem negar a influência desta corrente no cenário nacional, o que interessava era descrever aquilo que se constrói - no discurso e na prática- como ateísmo no cotidiano do ativismo local, em sua concretude e especificidade, evitando qualquer julgamento a respeito de se o resultado constitui ou não um ateísmo legítimo, consistente ou mesmo um "verdadeiro" ateísmo.

Considerado que a pergunta passou a recair sobre o ateísmo em sua existência social, o segundo movimento consistiu em abordar este ateísmo, ao mesmo tempo, como oposição e como parte do sempre vital campo religioso brasileiro, sem optar por uma ou outra dessas alternativas. $\mathrm{O}$ argumento do trabalho explorou tanto os aspectos que permitem considerar o movimento ateísta como um integrante a mais dentro da diversidade de alternativas religiosas existentes no cenário local, quanto aqueles -esgrimidos pelos próprios ateus- que o colocam como algo oposto e exterior a esse conjunto. Em suma, a ambiguidade foi considerada constitutiva do movimento ateísta tal como se configura no Brasil e foi, portanto, abordada como um aspecto central a ser descrito e compreendido e não como um problema a ser resolvido.

Abandonando qualquer pretensão de completude nem de exaustividade, metodologicamente a estratégia consistiu em iniciar a indagação pelos sites web das iniciativas ateístas já referenciadas nos poucos trabalhos existentes -que são também as mais conhecidas (em particular a ATEA -Associação brasileira de Ateus e Agnósticos e a LiHS -Liga Humanista Secular)- para rastrear a partir delas possíveis associações, grupos e iniciativas afins. Embora o trabalho começasse necessariamente pela Internet, o objetivo era chegar a eventos, reuniões, campanhas ou similares de caráter presencial onde realizar observação participante e conhecer pessoalmente os "ateus de carne e osso" que animavam a profusa atividade observável online. A empreitada resultou mais dificultosa do que o esperado: os ativistas se mostravam, em geral, desafetos ao contato direto, os encontros eram cada vez mais escassos e suas organizações funcionavam quase por completo de forma virtual. Ao todo, parecia se tratar de um movimento aglutinado através das novas tecnologias e feito possível por estas, embora não se pensasse nesses termos nem fosse, estritamente falando, redutível a suas manifestações virtuais. 


\section{As redes ateístas}

Esta busca, realizada em particular através das mídias sociais, levou mais de um mês de trabalho virtual para identificar o primeiro evento ateu em vigência durante o período. A maior parte dos anúncios, de fato, correspondiam a eventos passados, sem continuidade no momento do trabalho de campo. Tratava-se de um encontro de ateus que seria realizado em São Paulo no dia 15 de outubro de 2017. O evento, conhecido e divulgado como "Bar dos Hereges", acontecia mensalmente e consistia em reuniões de confraternização abertas ao público e realizadas sempre num bar nos sábados pela tarde. Considerando que o achado surgiu com menos de uma semana de antecedência, não foi possível viabilizar a participação na edição correspondente ao mês de outubro de 2017, porém, entrei de imediato em contato com os organizadores e comecei os preparativos para comparecer ao encontro de novembro. O fato do evento contar com um calendário predefinido para o conjunto do ano facilitou, em muito, estes preparativos.

Posteriormente foram detectados outros eventos. Um churrasco entre ateus publicitado na página Mundo Ateu e no grupo da ATEA, os encontros da Associação de Racionalistas Céticos e Ateus (ARCA) em Fortaleza, chamados de COMAAFOR (Confraternização Mensal de Ateus e Agnósticos de Fortaleza), os encontros saganistas em diversas cidades do país, o Picnicateu da Associação Ateísta do Planalto Central (APCE) e o Churrasco da Paixão organizado pela Associação Ateus de Pernambuco (APE). Outros eventos vieram como resposta a averiguações minhas, que costumava perguntar pela realização de encontros aos expoentes de iniciativas que já tinham organizado eventos no passado. Foi somente desse modo que fiquei sabendo da comemoração do Darwin Day pelo grupo de ARCA em Rio de Janeiro, que deixou de divulgar seus eventos no Facebook.

Ora, o trabalho de campo etnográfico não exigia apenas tomar conhecimento dos eventos, mas também fazê-lo a tempo para viabilizar a participação. Com efeito, como os encontros são realizados em diferentes cidades do Brasil, a realização do trabalho de campo etnográfico exigiu tempo hábil para a preparação das viagens necessárias. Muitas vezes os eventos eram noticiados com escassos dias de antecedência, outras eram inclusive marcados sobre a data, o que fazia inviável a participação. Logicamente, também entrou em consideração o fator econômico e temporal: houve eventos aos que não se conseguiu assistir porque excediam o orçamento disponível e encontros que coincidiam ou eram muito próximos de outros que se julgaram prioritários. Ao todo, assisti a 
duas edições do Bar dos Hereges (novembro de 2016 e janeiro de 2017), um encontro do grupo da ARCA no Rio de Janeiro (fevereiro 2017), um encontro saganista em Curitiba (março 2017) um encontro da APCE em Brasília (março 2017) e duas edições da COMAAFOR ligados ao grupo da ARCA em Fortaleza (maio e agosto de 2017) e, além destes, a um churrasco eventual, convocado através de um grupo de Facebook sem uma organização estável por trás.

Não foi possível assistir ao Churrasco da Paixão, evento realizado a cada sexta-feira santa em Recife por um grupo denominado Ateus de Pernambuco devido ao alto preço das passagens para o nordeste no feriado de Páscoa somado à pouca antecedência com que foi marcado o evento (duas semanas). Tampouco pude comparecer à Confraternização Mensal de Ateus e Agnósticos do Rio de Janeiro (COMAARJ/ARCA) de dezembro de 2016 por ter sabido do evento três dias antes, nem ao encontro saganista do Rio de Janeiro de março de 2017 por ser realizado em data muito próxima ao encontro da APCE em Brasília. Outros eventos, que esperava assistir, acabaram não acontecendo, notadamente o Congresso Humanista Mundial a ser organizado pela LiHS em São Paulo em agosto de 2017 e o Encontro Nacional de Ateus que era realizado anualmente em Rio Branco no Acre e foi descontinuado em 2017. Por outro lado, compareci sim à Marcha para Satanás de janeiro de 2017 em São Paulo, mas o evento por motivos que não consegui esclarecer não aconteceu.

Aliás, esta imprevisibilidade demonstrou ser uma característica constante dos encontros de ateus e põe a descoberto as dificuldades pelas quais passa o autodenominado movimento. Quer dizer, a dificuldade não era apenas do trabalho de campo, mas do campo mesmo. Os eventos de ateus são escassos e contam com uma organização mínima, já que mínimos são os grupos e estruturas que lhes fazem acontecer. De todos os eventos mencionados, apenas O Bar dos Hereges e as COMAAFOR aconteceram regularmente durante o período da pesquisa de campo (setembro de 2016 a setembro de 2017). Outros tiveram um calendário relativamente regular no passado, mas se tornaram esporádicos com o tempo ou mesmo deixaram de acontecer. Não são raros, por outro lado, os eventos mais ou menos ocasionais, que se organizam à margem de qualquer calendário, geralmente por iniciativa de um indivíduo ou um pequeno grupo.

Revisando o histórico de eventos que foi possível reconstituir, observa-se que encontros ateus foram mais estáveis no passado, mas perderam vitalidade nos últimos dois ou três anos. Destaca-se, em particular, o caso do Encontro Nacional de Ateus que teve sua primeira edição em fevereiro 2012, foi realizado em várias cidades simultaneamente e resultou da 
conjugação de esforços de várias iniciativas ateístas, a saber a Sociedade Racionalista, a ATEA, e o hoje abandonado blog Ateus do Brasil, entre outros. O evento foi repetido nos dois anos seguintes, sempre em fevereiro, e foi realizado novamente com o concurso de várias organizações e em várias cidades. O formato descentralizado, no qual cada grupo tomava autonomamente a iniciativa de organizar o evento na própria cidade, não impediu que este assumisse em alguns locais a formato de congresso, com reserva de auditório e programação de palestras, enquanto que em outros permaneceu como reunião de confraternização, grupo informal de debates no melhor dos casos ${ }^{3}$.

A partir da sua quarta edição, em 2015, o ENA foi continuado somente pelos seus organizadores no Acre. Passou a acontecer apenas em Rio Branco (apesar do epíteto de nacional) no seio da Universidade Federal do Acre, organizado por um grupo de estudantes e o auxílio de professores. Com tintes de evento ao mesmo tempo acadêmico e cultural, passou a contar com apresentações artísticas, além das palestras, e a dar direito a certificado aos participantes. Em 2014 o ENA foi realizado no mês de maio, em coincidência com o dia dos trabalhadores e sob o título "Ateísmo e Política" homenageou o "ateu materialista por excelência" Karl Marx. Em 2016 o evento foi dedicado a homenagear a figura de Alan Touring e debater o preconceito contra ateus. Desta vez, o ENA contou com várias atrações, espalhadas entre os meses de julho e agosto, a saber, palestras, exibições de filmes e apresentações musicais.

Em 2017 o evento foi descontinuado. Tinha entrado em contato com os organizadores, os que meu incluíram no seu grupo de WhatsApp, onde esperava conhecer a data com a maior antecedência possível e assim viabilizar a viagem para Rio Branco. Com o passar dos meses foi se fazendo claro que o encontro não aconteceria. Mais tarde, seu principal impulsor reconheceu dificuldades de financiamento e empecilhos pessoais. Nos anos anteriores o ENA tinha sido organizado dentro da universidade, com o apoio de um professor e com financiamento obtido através dos editais de apoio a eventos culturais da instituição. No ano em curso (2017) o impulsor do evento se encontrava finalizando seus estudos, o que lhe restava tempo e também o estatuto de aluno, necessário para a organização do evento 
dentro da universidade. Ficou evidente, com isso, a dependência dos esforços de uma única pessoa para que o encontro acontecesse.

As confraternizações mensais ligadas à ARCA iniciaram em 2014 em diferentes cidades do país. Em termos práticos, a ARCA constitui um endereço virtual que, assim como outros, reúne ateus de diferentes pontos do país. Os encontros mensais surgem como iniciativa de um seguidor, ou de um pequeno núcleo, e são divulgados pela página, além de ganhar o nome padronizado com as iniciais da cidade onde acontecem e numeração consecutiva para contabilizar as edições. As Confraternizações de Ateus e Agnósticos do Rio de Janeiro, São Paulo e Feira de Santana (BA) iniciaram todas em 2014 mas tiveram sortes diferentes com o tempo ${ }^{4}$. A COMAASP teve apenas cinco edições, entre agosto e dezembro de 2014. Posteriormente, deixou de acontecer ao menos como encontro aberto, o que não exclui eventuais reuniões privadas dos antigos frequentadores. As COMAAFS aconteceram regularmente até finais de 2015, em 2016 houve dois encontros na primeira metade do ano e depois disso não foram retomados. Ao todo, foram realizadas 14 COMAAFS.

As COMAARJ, por sua parte, aconteceram regularmente e com relativo sucesso até dezembro de 2016. Depois disso, os frequentadores continuaram se reunindo, mas antes como um grupo unido por interesses comuns e uma relação de confiança construída que como um evento aberto ao público. O encontro da ARCA no Rio de Janeiro do qual participei apresentava estas características. Foi combinado pelo WhatsApp entre os membros do grupo e fui convidada a participar como pesquisadora, mas não houve divulgação para que anônimos comparecessem. Indaguei aos organizadores sobre esta mudança e alegaram o que muitos outros impulsores de iniciativas ateístas alegaram: desgaste, cansaço, escasso sucesso na convocatória. Desde esse ponto de vista, focar nos ateus conhecidos, aqueles de provada perseverança no comparecimento aos eventos, aqueles que se tornaram amigos e partilham interesses e opiniões, pareceu simplesmente lógico.

As COMAAFOR, talvez pelo fato de serem mais recentes, são as únicas confraternizações da ARCA que continuam vigentes conforme a ideia original. As reuniões iniciaram em agosto de 2016 por iniciativa de uma ateia que achou a página da ARCA procurando informação sobre o tema na internet. Ela se disponibilizou a organizar as reuniões e a ARCA forneceu a plataforma de divulgação. Realizam-se mensalmente desde

Interessa mencionar que em 2015 houve apenas uma edição da COMAABRA, em Brasília, que não teve continuidade. 
seus inícios e reúnem uma boa quantidade de pessoas, maior às vezes que o Bar dos Hereges de São Paulo. Porém, como nos outros casos, a realização efetiva dos encontros depende do esforço de uma pessoa, que no caso disponibiliza o salão de festas do prédio onde mora, fornece parte das comidas e das bebidas e se ocupa de boa parte do trabalho de divulgação ${ }^{5}$.

O Churrasco da Paixão começou ser realizado em 2013, por iniciativa de um grupo que, como os outros, possui suas bases no mundo digital. Continua a ser realizado a cada ano, na sexta-feira da semana santa, que é invertida e celebrada com um churrasco nas praias do Recife. No restante do ano, a autodenominada organização Ateus e Agnósticos de Pernambuco (APE) permanece predominantemente como uma iniciativa de difusão de material digital sobre ateísmo e em defesa do Estado laico. No passado tem participado dos Encontros Nacionais de Ateus em Pernambuco, promovido campanhas de doação de sangue e realizado reuniões com um tom mais sério que os churrascos, mas essa movimentação não aconteceu durante o período do trabalho de campo e até o momento da escrita deste texto a situação permanece a mesma ${ }^{6}$.

A organização de churrascos como ocasião de convivência entre ateus era de praxe alguns anos atrás na Associação de Ateus do Planalto Central. Eles organizavam o Churrasteu, sem um calendário fixo, com entre duas e quatro edições por ano. Os churrascos tiveram início em 2011 e se estenderam até agosto de 2016, totalizando 17 edições. Deixaram de acontecer pelo motivo habitual: desgaste dos poucos que em efeito se disponibilizavam a organizar os eventos. Em março de 2017 houve uma última edição, com uma ligeira mudança, em lugar de um churrasco foi feito um piquenique, precisamente para diminuir os esforços de organização. De todas maneiras, a experiência não se repetiu e desde março de 2017 não houve outra edição das confraternizações da APCE.

O Bar dos Hereges começou a ser realizado entre finais de 2012 e inícios de 2013. Durante o transcurso do trabalho de campo os encontros mudaram o nome original, passando a ser denominados "Encontro Ateísta". Além disso, mudou-se a política de realizá-los sempre no mesmo local para ir variando entre diferentes pontos da cidade. Ambas as mudanças foram com a intenção de captar mais seguidores, já que a convocatória era tida por escassa. Para tanto, também houve publicidades pagas no 
Facebook, com recursos que, à falta de outra forma de arrecadação, saíram do próprio bolso dos organizadores.

\section{A importância da iniciativa individual no movimento ateísta}

Como se faz evidente a partir das descrições acima, não há exatamente organizações bem constituídas por trás dos eventos ateístas observados, mas grupos mais ou menos estáveis agregados por líderes individuais, uma sorte de empresários morais, que tomam a iniciativa de levar adiante os encontros e, com isso, fazem o ateísmo existir como movimento no Brasil. Do histórico de eventos resumido acima é possível concluir que nas ocasiões em que falta o indivíduo que assume para si a tarefa de organizá-los, os eventos simplesmente deixam de acontecer. Segue-se daí que não há, por trás desses eventos, estruturas duradouras, instituições no sentido da sociologia clássica, com funções, cargos e sucessão dos cargos (Weber, 1974). Embora as situações variem entre os grupos, todos eles têm em comum um alto grau de instabilidade, desorganização, e vulnerabilidade frente aos imponderáveis da vida pessoal dos membros e da vida social e política do país.

O Bar dos Hereges iniciou como uma iniciativa do Projeto Livres Pensadores, um grupo dedicado à divulgação científica na Internet, isto é, uma equipe por trás de um blog de ciências. Pouco depois, passou às mãos do NASP, uma associação informal constituída por um grupo que se conheceu no primeiro ENA realizado em São Paulo. Hoje em dia, o NASP não constitui mais do que uma página em Facebook e o Bar dos Hereges, transformado em Encontro Ateísta, tem se tornado um projeto em si mesmo levado adiante por um dos membros do NASP que realiza o trabalho efetivo de organização e comparece de fato aos encontros. É apoiado materialmente e à distância por outro desses membros originais, que aporta dinheiro e conhecimentos na área de sistemas de informação para contribuir na divulgação. Fora eles, o Encontro Ateísta possui alguns frequentadores, que eventualmente discutem assuntos relacionados com a organização, mas não contribuem efetivamente com esta.

A ARCA, por sua vez, funciona como uma plataforma que facilita a realização de eventos de confraternização, mas não tem e nunca conseguiu ter uma constituição formal. A ARCA conheceu épocas com confraternizações mensais em diferentes cidades do país cada uma organizada por um núcleo independente e autogestionado. Nunca teve uma organização centralizada, porém. A iniciativa original surgiu no Rio de Janeiro, outrora o núcleo mais ativo, que ainda conserva a administração dos endereços virtuais. Este grupo teve uma fratura após o impeachment da Presidenta 
Dilma Rousseff, devido a diferenças políticas irreconciliáveis entre seus participantes. Os que permaneceram são os que descrevem a crise política como golpe e se identificam com a presidente deposta. Seja por esta ruptura, seja pelo desgaste de seu principal impulsor, também envolvido em outros projetos além de seu emprego regular, o grupo tem se tornado um grupo de amigos, com interesses e ideias afins, que se reúnem periodicamente, de forma privada e informal, sem agenda definida.

O núcleo de Fortaleza, o único com confraternizações regulares vigentes, surgiu por iniciativa de uma mulher que, como já se mencionou, é quem se encarrega até hoje da maior parte do trabalho efetivo por trás dos encontros. Estas confraternizações reuniram um grupo mais ou menos estável de frequentadores, entre os quais um ativista virtual, que tinha por sua vez reunido um grupo de seguidores num grupo de WhatsApp que aspirava a se elevar como organização ateísta atuante a nível nacional. Apresentou ao grupo da ARCA em Fortaleza o projeto de unir ambos os coletivos, sob a identidade visual que ele mesmo tinha criado para o coletivo. Após acalorados debates, a união foi aceita, o grupo passou a se chamar de Ateia da Razão, assumiu a logomarca do grupo parceiro e somou uns poucos participantes a mais nas confraternizações mensais, que continuaram a ser promovidas pelo site da ARCA e denominadas segundo o padrão utilizado por esta. Na prática e apesar da existência de um "conselho" de diretores, as reuniões correm, em sua maior parte, por conta da impulsora original.

Como no Rio de Janeiro, o grupo sofreu uma fissura com a consequente conformação de um subgrupo com uma tônica diferente. Este segundo grupo se constitui basicamente como um círculo de estudo e discussão, baseado na leitura de textos acadêmicos, boa parte deles ligados ao marxismo. Se diferencia do grupo que lhe deu origem pela marca política e a tendência explícita ao polo esquerdo desse espectro. Contudo, seus participantes continuam participando das COMAAFOR, e tomando parte nos debates sobre temáticas científicas priorizadas nesse contexto. Não houve, portanto, enfraquecimento do grupo que inclusive, tem iniciado um projeto que excede as confraternizações mensais e as discussões no grupo de WhatsApp. Sob o leit motiv "criança com razão" organizam doações periódicas de livros a crianças de uma comunidade carente dos arredores de Fortaleza. Assim mesmo, discutem a possibilidade de se tornar uma organização formal, porém com poucos avanços efetivos. Apesar das mudanças, as confraternizações mensais continuam a ser a principal atividade do grupo e continuam a recair, principalmente, no trabalho de sua impulsora original. 
A pesar disto, a impronta que a ativista da aos encontros é por vezes questionada pela sua semelhança com "reuniões de igreja". Nas conversas iniciais entre os ateus que iam chegando na COMAAFOR de maio de 2017, entrou em discussão a possibilidade de se marcar os próximos eventos num bar, onde -alguém opinou- haveria mais convocatória e seria mais divertido. Mais tarde, a própria organizadora explicou para mim uma de suas preocupações é evitar a descaracterização do grupo, por isso mantém o formato baseado em apresentações sobre um tema predefinido e sempre afim ao ateísmo, com um espaço posterior para discussão. A proposta de certa forma similar à de um congresso acadêmico exige um local apropriado, e por isso as reuniões são realizadas no salão de festas do prédio onde mora, um espaço que é ao mesmo tempo privado e tranquilo. Mesmo reconhecendo que é esse mesmo formato que levanta críticas, não possui planos de mudança. Ela não quer a COMAAFOR se torne apenas um encontro de amigos que se reúnem conversar sobre qualquer coisa.

Ainda mais do que nos casos anteriores o funcionamento da APCE depende da atividade de sua fundadora, quem por vezes não se distingue da própria organização. Ela assume pessoalmente os custos financeiros e se ocupa pessoalmente do conjunto do trabalho da organização. Ela participa do comitê de liberdade religiosa do Distrito Federal em nome da APCE, oferece palestras quando solicitada e gerencia os endereços virtuais da associação. Nos inícios se ocupava igualmente da organização dos churrasteus, que aconteciam em sua própria residência. Com o tempo desistiu do trabalho ligado à confraternização que considera pouco sério e eficaz para a causa a que se dedica. Este foi delegado a alguns dos jovens frequentadores do evento, com as consequências mencionadas acima. A diferença de perspectiva entre estes e a fundadora é evidente: enquanto esta última preferiria aproveitar estas ocasiões para discutir temas com uma pauta definida, os jovens que assumiram a empreitada (e aparentemente a maior parte dos frequentadores) não mostram outro interesse que a confraternização informal.

Logo após a chegada no piquenique de março de 2016, foi possível perceber a tensão entre estas duas facetas da APCE. No relato da própria presidente, há um setor que apenas "quer se reunir para beber $e$ socializar", sem uma pauta definida nem muitas formalidades. O que querem é encontrar pessoas que pensam de forma similar e passar bons momentos, tendo pouco interesse na construção de um movimento no sentido político do termo. Este último é tarefa quase solitária da fundadora, quem possui longa trajetória na militância política e nos movimentos sociais. Para ela, o ativismo ateísta e todo o esforço que supõe só faz sentido nestes termos, se for para criar mudanças sociais que excedem o 
grupo que as impulsiona. O divertimento e mesmo a criação de laços são para ela desnecessários se deslindado deste trabalho sério e o compromisso constante com este.

A ATEA seguiu uma trajetória similar no que tange à organização de encontros informais: desistiu deles e é por isso que não aparece na contagem de eventos realizada acima. Na perspectiva do seu principal impulsor e rosto visível, os recursos a todas vistas escassos com que conta a associação são melhor empregados se aplicados em causas "sérias" como o ativismo judiciário. A organização de encontros consome tempo, dinheiro, trabalho sem resultados sensíveis. Com efeito, nada garante que os eventos obterão convocatória suficiente para justificar os esforços e menos ainda que dessa convocatória surgirão voluntários comprometidos com a causa e dispostos a de fato trabalhar na organização. Perante recursos extremamente escassos e uma organização que se mantém sobre os ombros de não mais que meia dúzia de voluntários focar naquilo que se mostra sério e sólido não parece desacertado.

Esta hierarquia de prioridades se fez evidente durante a assembleia anual da associação de janeiro de 2017, ocasião em que um dos presentes refletiu que era necessário fortalecer a forma de pensar dos ateus e que para isso era necessário fazer reuniões mais amiúde, para "trocar ideias" e socializar. Ele sugeriu a ATEA organizar encontros numa biblioteca que ele frequenta, e acrescentou que tais reuniões poderiam ser divulgadas pelo site da associação, e que as pessoas deveriam ser convocadas para "debater". Pelas expressões dos diretores presentes, notei que a ideia do senhor não levaria um parecer favorável. Mencionando os estatutos, um deles respondeu que "promover encontros sociais não é o objetivo da associação". Acrescentou que embora isso, a ATEA não é contra esse tipo de encontros e que incentiva quem se disponibilizar a fazer. Outro, de forma mais incisiva disse que não ajudava "apenas propor", que "era necessário fazer". Alguém lembrou que o "Bar dos Hereges" se ocupa dessa tarefa há muito tempo, e não consegue reunir mais de 20 pessoas.

Em conversas posteriores, aquele entre os diretores que gentilmente se disponibilizou a colaborar com a pesquisa, manifestou seu descontentamento com aqueles que, como o senhor da reunião, fala o que a associação deve fazer, mas não se envolvem nem aportam trabalho. Ele se encontrava visivelmente cansado, pois não tinha dormido a noite anterior preparando a prestação de contas que seria apresentada na assembleia. Além disso, teve de lidar com um problema de última hora antes da formalidade começar: o diretor que tinha facilitado seu escritório como local do encontro esqueceu do compromisso e estava fora da 
cidade nesse dia. Meu informante acabou oferendo a própria casa como local, mas teve que se ocupar de avisar os associados da mudança além de pensar no transporte daqueles que iam chegando no primeiro endereço. O contratempo, assim como o fato deste recair nos ombros de um par de pessoas não pareciam um fato isolado, mas o cotidiano da organização. Na prática, quando se sugere a ATEA fazer tal o qual coisa, se está pedindo isso aos poucos indivíduos que de fato a levam adiante.

Tomando ciência desta situação, mencionei ao meu interlocutor que as igrejas conseguem seguidores e colaboradores com mais facilidade porque vinculam os fiéis de forma pessoal. Já o ateísmo, com toda sua coerência e racionalidade, não atinge esta faceta por isso as pessoas não se comprometem. Era uma forma sutil de sugerir que não era má ideia a criação de espaços de socialização ateus, desde que poderiam dar lugar a esse envolvimento pessoal para atrair mais pessoas interessadas em trabalhar para o movimento. Não funcionou. Embora meu interlocutor concordasse com que é difícil que as pessoas se comprometam com causas abstratas como a "laicidade do Estado", não via isso como algo a ser mudado. Para ser engajado e responsável e por isso um colaborador fiável, o ateu em questão deve ser, necessariamente, um ateu racional. Aparentemente, confraternizações e amizades vão contra a ideia que ele tem de militância ateísta: se precisa desse tipo de incentivo, não é adequado para a tarefa.

Este mesmo diretor opina que é difícil achar ateus firmes na sua posição, que tenham chegado e se mantenham nela por puro pensamento racional. Ateus racionais e, por cima, comprometidos, há poucos, a diferença dos "ateus passionais" que abundam. Segundo ele mesmo explica, trata-se de pessoas que se fazem ateias por algum problema pessoal, geralmente um desengano amoroso, e não pelo "uso da razão". Podem estar muito empolgados e se envolver com a causa, porém, essa condição por definição não dura muito. Opina que é preciso ter cuidado com essas pessoas, já que podem desistir do ateísmo a qualquer momento e depois "se voltar contra", ou simplesmente abandonar a causa de um dia para o outro. Os colaboradores que buscam (e muito dificilmente conseguem) são precisamente este tipo de racionalistas consistentes e constantes que julgam mais fiáveis. 
Ora, em matéria de iniciativa pessoal, um caso limite foi um churrasco ${ }^{7}$ de ateus ao qual se chegou através de um anúncio num grupo de Facebook. O evento, totalmente informal e de edição única, foi organizado por um ativista virtual, quem teve a ideia, assumiu a iniciativa e se ocupou da organização. Aparentemente a ideia surgiu de discussões num grupo de WhatsApp no qual os participantes interagem faz já um tempo. O evento foi divulgado através de diferentes grupos de Facebook, porém a organização recaiu sobre um único indivíduo. Este se encarregou de reservar o espaço, comprar e preparar a comida, e manter os participantes informados sobre os horários, o que levar, e demais detalhes. Embora tenha estipulado uma contribuição financeira por parte de cada assistente, uma parte substancial dos custos saíram do próprio bolso (incluindo o almoço da pesquisadora), bem como o trabalho efetivo de preparação de um almoço ao qual não faltou absolutamente nada.

Questionado sobre a motivação para levar adiante semelhante trabalho, o ativista esboçou uma explicação na qual o paralelismo com a vida religiosa não era (como costuma ser) pejorativo. De fato, explica sua iniciativa através de uma comparação com "as religiões e os crentes" que apesar de todas as críticas que se lhes fazem, têm algo que falta aos ateus: "ORGANIZAÇÃO e FRATERNIDADE". Ele entende que ateus por muito tempo têm estado sozinhos e que "somos uma minoria que tenta se bater e que estamos saindo dos nossos armários". Para ele, é "hora de dar um pontapé nisso", "hora de falar" e por isso decidiu tomar conta da organização do encontro. Relata que a ideia partiu dele mesmo e amadureceu durante dois anos no grupo de WhatsApp do qual participa junto com outros ateus "espalhados pelo Brasil". O propósito do evento era, precisamente o de proporcionar a oportunidade de se conhecerem pessoalmente após tanto tempo de interação virtual.

\section{Uma vocação ateísta?}

Alguns lineamentos gerais podem ser apontados a partir do exposto até aqui. Em primeiro lugar que o ateísmo organizado é apenas organizado de uma forma embrionária e contingente, dependente em última instância da iniciativa de indivíduos pontuais, que sacrificam tempo livre e dinheiro próprio em prol da causa. A causa é correntemente entendida ao modo dos movimentos sociais, e assume definições como luta pelo preconceito contra ateus, pelo reconhecimento do ateísmo como opção religiosa

No Brasil, os chamados "churrascos" são uma forma bem popular de reunião festiva. Geralmente convocam familiares, amigos ou, como neste caso, pessoas com um vínculo informal e interesse em confraternizar. Costumam durar várias horas e estar servidos por carnes, acompanhamentos e aperitivos que vão sendo distribuídos gradualmente, além de bebidas a vontade, em particular cerveja. 
válida e, ao mesmo tempo, defesa da laicidade do Estado. Contudo, a instabilidade e informalidade da maior parte dos grupos, as dificuldades em constituir estruturas duradouras, e a excessiva individualidade por trás das iniciativas por vezes faz duvidar da adequação do termo. Por momentos o chamado movimento não se distingue de uma reunião de amigos ou de conhecidos com interesses comuns.

Ao mesmo tempo, são frequentes os questionamentos, vindos tanto do exterior quanto dos próprios participantes, quanto à semelhança com a religião organizada. O fantasma da religião parece assombrar com frequência os eventos e grupos ateístas, como consequência, veem questionada a legitimidade de seu ceticismo e a substância de sua descrença. Inclusive para os próprios participantes qualquer tentativa de organização formal ou de definição da causa além do mínimo necessário é vista como uma contradição nos próprios termos, inclusive como uma traição à causa mesma. Assim, nos encontros não se admite outra cerimônia ou padronização para além do acerto de uma pauta de discussão, no melhor caso, o das COMAAFOR; nos restantes, se faz questão de que predomine a informalidade e o tom festivo e distendido. A bebida, e principalmente as bebidas alcoólicas marcam, no caso típico, que não se trata de ofícios religiosos. Como assinala Minois (2014), o bar foi pelo menos desde a Idade Média o contraponto da igreja.

Para além dos eventos, parece existir uma resistência à formalização nos grupos. Não se trata apenas da dificuldade de conseguir convocatória suficiente, ou da falta de compromisso daqueles que sim comparecem. As reuniões, assim como os grupos (se é possível chamá-los desse modo) resistem à formalização, à padronização, ao comportamento de corpo. As discussões resistem a qualquer formulação da causa além da compreensão do ateísmo como a reunião daqueles que não acreditam em deus. Qualquer tentativa de transcender a definição pela negativa colide com comparações com igrejas e suas regras teológicas e litúrgicas, ortodoxias e ortopráxis (Calavia-Sáez, 2009). O movimento ateísta resiste a definição, inclusive como movimento. Resiste, sem muito sucesso, à comparação com movimentos religiosos. Resiste a organização, a definição clara de um público-alvo, de uma prática específica e de um conjunto de ideias.

Os consensos são escassos e no caso típico associam a descrença em divindades com o uso correto da razão. Esta pode ser entendida de várias formas, mas na maior parte dos casos é associada com as ciências exatas e naturais, o uso do método científico, a matemática e a lógica. Discute-se também a situação de preconceito vivida pelos descrentes numa cultura 
amplamente religiosa. Da mesma medida, ou talvez maior, é o interesse pela crítica das religiões estabelecidas em todos os fatores que fazem a sua existência efetiva. Critica-se a consistência das escrituras sagradas, o propósito da investigação teológica, as incongruências do funcionamento institucional, a hipocrisia das normas éticas e morais, o comportamento dos seus líderes, o bizarro de suas práticas rituais, o absurdo de suas crenças teológicas, e assim por diante. O alvo é sempre o cristianismo, em particular em suas vertentes católica e evangélica, predominantes no Brasil. Por extensão, os questionamentos atingem também tal ou qual prática ou crença que possa ser enquadrada como superstição ou pseudociência. Desde logo, o que se entende por superstição e pseudociência pode variar em certa medida, caso a caso.

Ora bem, o que se observa aqui é um punhado de agrupações instáveis e minimamente estruturadas com uma agenda de atividades igualmente irregular. Tanto as agrupações quanto as atividades são mantidas graças ao trabalho de uns poucos líderes, e no caso de algumas iniciativas, apenas um indivíduo. Estas pessoas em muitos casos criaram as próprias agrupações, aglutinaram os participantes, e empreendem sua agenda de atividades como um projeto pessoal, como uma empresa que lhes diz respeito. Como explicar semelhante investimento de tempo, esforço e, inclusive, dinheiro? Como estes líderes entendem e explicam a tarefa que assumem para si? Quais os sentidos atribuídos à empreitada? Até os eventos mais informais consomem tempo de trabalho, exigem o investimento de dinheiro e muitas vezes sequer atingem a mínima convocatória que os justifique. Não há benefícios materiais ou simbólicos aparentes, a não ser a tentativa de liderar coletivos que apenas se entendem como tais e rejeitam explicitamente as lideranças.

Questiona-se aqui sobre a pertinência do conceito weberiano de vocação como via interpretativa possível para o acionar destas lideranças. Resgata-se, em primeiro lugar o contraponto que a noção faz ao utilitarismo que visa satisfações imediatas. Como conceito, porém, faço referência antes a uma noção com diversos matizes do que a uma definição fechada e unívoca. É esta plasticidade, com efeito, o que habilita o exercício interpretativo sobre um fenômeno que insiste em se mostrar incompleto ou falho se comparado com projetos religiosos ou políticos propriamente ditos, àqueles aos quais o conceito se refere no caso típico. Em primeiro lugar, e descartando a denotação mais importante da noção, não há aqui, por definição, chamado divino que possa ser invocado como justificativa para o sacrifício realizado (Weber, 2003). Entre racionalistas e materialistas, não há ordem transcendente a ser colocada na equação, 
tanto menos ordem transcendente dotada de agência, capaz de induzir a tomada de decisões e cursos de ação determinados.

De uma forma menos óbvia, também não cabe utilizar aqui a noção de vocação como carisma pessoal. Na tipologia weberiana das formas de dominação, aquela marcada pelo carisma se distingue pelo personalismo, a paixão e a emoção. A dominação carismática se opõe à dominação legal racional e também à tradicional pelo fato de estar atrelada à figura excepcional de um líder que é seguido em virtude de suas características individuais. Embora os projetos observados dependam de fato de líderes individuais, em nenhum dos casos estes se ajustam à figura do líder carismático que tem, ele mesmo, algo de divino. Entre pretensos racionalistas, paixão e emoção são antes falhas e debilidades do que valores e, portanto, se não eliminadas devem ser pelo menos mascaradas.

No caso típico, os indivíduos que tomam iniciativas como as mencionadas não possuem o perfil expansivo e convocante das lideranças carismáticas típicas. Embora se esforcem por convocar pessoas para a causa, costumam manter um perfil modesto, tendem a evitar ser o centro das atenções, partilham decisões com os seguidores que consideram pares e não investem em publicidade de si mesmos. Em alguns casos trata-se de pessoas com poucas habilidades sociais ou pouco interesse em desenvolvê-las. Eles evidenciam, no polo oposto, comprometimento com o projeto e um trabalho constante e consistente em prol dele. Se ocupam da causa, tomam a iniciativa, investem, e muitas vezes não obtêm os resultados esperados. Os seguidores são poucos, e os poucos que há tipicamente não assumem a responsabilidade para si, não fazem própria a empresa como aqueles que a começaram, simplesmente se isentam do compromisso se limitando a assistir aos encontros.

Ora, o afinco no trabalho voluntário que sustenta estas iniciativas conduz a outra das conotações da concepção de vocação: aquele da autorrealização moral no trabalho cotidiano. A novidade que trazia o ensaio weberiano sobre a ética protestante e o espírito do capitalismo (2003) era o significado religioso que as tarefas profissionais mundanas passaram assumir a partir da Reforma Protestante. A partir de Lutero e em particular Calvino, o trabalho cotidiano começou a ser caminho e também prova para a salvação da alma, passou a ser entendido como prática religiosa e transcendente e não apenas econômica, instrumental ou prática. Mais uma vez, este elemento não pode ser assumido para os casos aqui considerados. Ao menos não pode ser assumido sem trair os sentidos declarados pelos 
próprios sujeitos. Assim, o que resta é o trabalho mesmo que, na ausência de significado transcendente e de recompensas materiais, normalmente se mantém com dificuldades e decai após um tempo.

Isso deixa aberta apenas uma das conotações da categoria weberiana de vocação. Àquela que refere simplesmente à dotação de um indivíduo com as qualidades íntimas necessárias para uma causa determinada. Trata-se, claro, de uma acepção formal, que deve ser completada, em cada caso, com o significado singular da tarefa que se leva adiante. Ora, em que consiste a vocação para a iniciativa ateísta? Que qualidades um movimento semelhante exige daqueles que o articulam? Note-se que a questão passa aqui a referir aos meios e não aos fins, que não se questionam. As grandes bandeiras da causa ateísta, portanto, não estão em questão aqui, mas as condições para empreender tarefa semelhante.

Com isto se chega à questão do ethos que orienta a militância ateísta bem entendida. Com efeito, quando fala em vocação Weber se engaja em discussões a respeito da ética particular a determinada esfera de atividade quando esta transcende o mero interesse pessoal. Assim, em A Ética Protestante e o Espírito do Capitalismo, o autor mobiliza a noção alemã de beruf na explicação do ethos típico de certas seitas protestantes nas quais a perseguição sistemática de benefícios económicos contrastava com o ascetismo da vida cotidiana que vedava, precisamente, o aproveitamento desses lucros. De modo similar, em A Política como Vocação e A Ciência como Vocação, o autor se ocupa de distinguir as qualidades necessárias ao exercício da atividade política e científica quando estas são levadas adiante ao serviço de uma causa, daqueles casos onde esta falta.

É esta ética ligada ao compromisso com uma causa que daria -segundo esta perspectiva- sentido e consistência interna ao acionar. Ora, a partir do expressado até aqui é possível afirmar que a fidelidade com a causa ateísta exige, além de um compromisso individual firme com o trabalho organizativo, uma vigilância constante sobre as feições que o movimento assim composto vai adotando. Como bem lembram os críticos da descrença organizada e o sabem seus ativistas, a pior traição a causa é a transformação ou recaída em religião. Antes de mais nada, e visto que se busca fazer do ateísmo um posicionamento coletivo e público, é preciso fazê-lo sem devir igreja, congregação, sem configurar cultos ou rituais, sem sancionar dogmas nem preceitos de conduta, e em particular para as lideranças, sem investir profetas ou gurus. Não há nem pode haver carisma nem rotinização do carisma. 
Na prática, o desafio ateísta de se fazer coletivo sem devir religião adota duas vias: o caminho da informalidade, que privilegia a confraternização e a criação de vínculos, mas evita outras caracterizações, ou bem o caminho do trabalho institucional racionalizado orientado a fins de mudança social que resiste toda atividade supérflua a tais preocupações. Em ambos os casos, na tentativa de evitar a aproximação de qualquer forma que possa ser identificada como religiosa, se evita a padronização, a formalização, o estabelecimento de definições substantivas e vinculantes, o traçado de fronteiras sociais e simbólicas claras, a estabilização de uma visão de mundo comum, de normas de conduta ou mesmo de sinais diacríticos. O resultado de uma configuração semelhante é um movimento que recusa a constituição de grupos e a institucionalização além do mínimo necessário à existência como tal. Um movimento que não acaba, em suma, de se tornar coletivo e se assenta sobre o esforço tenaz dos poucos que têm a bem assumir a causa para si, como missão pessoal.

Entende-se daí que tocar iniciativas como as aqui descritas exija destas pessoas uma série bastante incomum de características, por vezes contraditórias. Exige liderar sem fazê-lo completamente, exige o convencimento de lutar por uma causa definida negativamente, exige uma postura constante de racionalidade, porém sem regras definidas que guiem a vida cotidiana e, sobretudo, uma racionalidade que não exclui lazer e espairecimento. Deve estar aberto a coordenar um movimento sem uma definição excludente do público que convoca, com seguidores que rejeitam a formalização e não se vinculam se não de forma pessoal e, no limite, circunstancial. A tarefa exige certo culto à razão científica, porém sem liturgias evidentes. Exige-se, em suma, articular um movimento sem fazê-lo completamente, sob pena de trair a própria causa que o anima. Exige, finalmente, a dedicação - frugal em recompensas- por algo que se deve manter sempre no limiar da existência social.

\section{Referências Bibliográficas}

Calavia-Sáez, O. (2009). O que os santos podem fazer pela antropologia? Religião e Sociedade, 29(2), 198-219. https://www.scielo.br/pdf/rs/v29n2/v29n2a10.pdf

Dawkins, R. (2006). The God Delusion. Houghton Mifflin.

Dawkins, R. (2007). Deus, um delírio. Companhia das Letras.

Dennet, D. (2006). Breaking the spell: Religion as a natural phenomenon. Viking.

Fernandes, R. (2015). Graças a Deus sou ateu: Humor e conflito entre ciência e religião nas comunidades neoateístas do Facebook (Dissertação de Mestrado). São Paulo: Pontifícia Universidade Católica de São Paulo. 
Franco, C. d. (2014). O ateísmo de Richard Dawkins nas fronteiras da ciência evolucionista e do senso comum (Tese Doutorado). São Paulo: Pontifícia Universidade Católica de São Paulo.

Gordon, F. (2011). A Cidade dos Brights: Religião, Política e Ciência no Movi-mento Neo-ateísta (Tese Doutorado). Rio de Janeiro: Museu Nacional, Universidade Federal do Rio de Janeiro.

Harris, S. (2004). The End of Faith: Religion, Terror, and the Future of Reason. W. W. Norton.

Hitchens, C. (2007). God is not Great: How Religion Poisons Everything. Twelve Books.

Hitchens, C. (2016). Deus não é grande: Como a religião envenena tudo. Globo Livros.

Latour, B. (2005). Reensamblar lo social: Una introducción a la teoria del actor red. Manantial. Minois, F. (2014). História do Ateísmo. UNESP.

Montero, P. y Dullo, E. (2014). Ateísmo no Brasil: da invisibilidade à crença fundamentalista. Novos estudos, 100, 57-79. https://www.scielo.br/pdf/nec/n100/0101-3300-nec100-00057.pdf

Moreira, L. V. (2014). Ainda encantados?: Neoateísmo e desencantamento do mundo (Dissertação Mestrado). São Paulo, Pontifícia Universidade Católica de São Paulo.

Takata, R. (4 de agosto de 2010). Em nome da diversidade. Fundação Perseu Abramo. https:// fpabramo.org.br/2010/08/04/em-nome-da-diversidade/

Testa, S. (2018). O ateísmo e a luta pela laicidade do Estado. Em M. Tadvald, H. Wynarczyk y M. Meirelles. Religião, Sociedade e Política: Miradas Socioantropológicas (pp. 31-44). Cirkula.

Testa, S. (2020). Oposição e parte: O movimento ateísta e o campo religioso brasileiro (Tese Doutorado). Universidade Federal de Santa Catarina, Florianópolis.

Weber, M. (1974). Economía y Sociedad: Esbozo de sociología comprensiva. Fondo de Cultura Económica.

Weber, M. (1993). El político y el científico. Alianza Editorial.

Weber, M. (2003). La ética Protestante y el Espiritu del Capitalismo. Introducción y edición crítica de Francisco Gil Villegas M. Fondo de Cultura Económica. 